\title{
Preparation of $\mathrm{Mn}_{3} \mathrm{O}_{4}$ Nanoparticles via Precipitation in Presence of CTAB Molecules and Its Application as Anode Material for Lithium Ion Batteries
}

\author{
Lin-Hui Wang ${ }^{1, \#}$, Long-Long Ren ${ }^{2, \#}$,Yu-Feng Qin ${ }^{1,}$ *, Jun Chen ${ }^{1}$, Hong-Ye Chen ${ }^{1}$, \\ Kai Wang ${ }^{3}$, Heng-Jun Liu ${ }^{4}$, Zhe Huang ${ }^{5}$, and Qiang $\mathrm{Li}^{4}$, * \\ ${ }^{1}$ College of Information Science and Engineering, Shandong Agricultural University, Taian, \\ Shandong, 271018 P. R. China. \\ ${ }^{2}$ College of Mechanical and Electronic Engineering, Shandong Agricultural University, Taian, \\ Shandong, 271018 P. R. China. \\ ${ }^{3}$ College of Electrical Engineering, Qingdao University, Qingdao 266071, P. R. China. \\ ${ }^{4}$ College of Physics, University-Industry Joint Center for Ocean Observation and Broadband \\ Communication, Qingdao University, Qingdao 266071, P. R. China. \\ ${ }^{5}$ Wuhan Maritime Communication Research Institute, Wuhan, Hubei, 430205 P. R. China. \\ ${ }^{\#}$ Co-first authors: \\ Lin-Hui Wang and Long-Long Ren contributed equally to this work. \\ *E-mail: qinyufeng@ sdau.edu.cn, liqiang@qdu.edu.cn
}

Received: 8 October 2021 / Accepted: 30 November 2021 / Published: 5 January 2022

The $\mathrm{Mn}_{3} \mathrm{O}_{4}$ nanomaterials were widely investigated due to their potential application as anodes for lithium-ion batteries. Uniform $\mathrm{Mn}_{3} \mathrm{O}_{4}$ nanoparticles with a suitable diameter of $40 \mathrm{~nm}$ were designed and prepared by the water bath method to solve the low conductivity and the pulverization during cycling. The $\mathrm{Mn}_{3} \mathrm{O}_{4}$ nanoparticles electrodes exhibited an initial discharge capacity of $1288 \mathrm{mAh} / \mathrm{g}$ with an initial coulombic efficiency of $65 \%$ at $100 \mathrm{~mA} / \mathrm{g}$. At $200 \mathrm{~mA} / \mathrm{g}$, the reversible capacity increased to $1345 \mathrm{mAh} / \mathrm{g}$ after 190 cycles. The specific capacity increased to $547 \mathrm{mAh} / \mathrm{g}$ and $691 \mathrm{mAh} / \mathrm{g}$ when back to $200 \mathrm{~mA} / \mathrm{g}$ and $100 \mathrm{~mA} / \mathrm{g}$, indicating the exceptional rate capability. The outstanding electrochemical performance of the $\mathrm{Mn}_{3} \mathrm{O}_{4}$ nanoparticles results from the suitable size of the nanoparticles and the increased conductivity during cycles. The $\mathrm{Mn}_{3} \mathrm{O}_{4}$ nanoparticles prepared with the water bath method have the potential application as anodes for lithium-ion batteries.

Keywords: $\mathrm{Mn}_{3} \mathrm{O}_{4}$ nanoparticles, Suitable size, Anodes, Lithium-ion batteries, Increased reversible capacity, Water bath.

\section{$\underline{\text { FULL TEXT }}$}

(C) 2022 The Authors. Published by ESG (www.electrochemsci.org). This article is an open access article distributed under the terms and conditions of the Creative Commons Attribution license (http://creativecommons.org/licenses/by/4.0/). 